\title{
Association between occupational exposure to domestic solid waste and dental caries: a cross-sectional study
}

\author{
Mariana Carvalho Andrade ${ }^{1}$ - Nara Santos Araujo ${ }^{1}$ - Maria Isabel Pereira Vianna ${ }^{2}$ - Maria Cristina Teixeira Cangussu ${ }^{2}$. \\ Isaac Suzart Gomes-Filho ${ }^{3}$. Daniel Araki Ribeiro ${ }^{4}$ - Patrícia Ramos Cury ${ }^{5,6}$ - Jean Nunes dos Santos ${ }^{7}$
}

Received: 15 April 2021 / Accepted: 9 June 2021 / Published online: 23 June 2021

(C) The Author(s), under exclusive licence to Springer-Verlag GmbH Germany, part of Springer Nature 2021

\begin{abstract}
Studies have shown that domestic waste collectors are exposed to toxicants including infectious pathogens, which may be linked to their oral health conditions. This cross-sectional study evaluated the dental caries and its associated factors among domestic waste collectors. A total of 301 adult men who worked for a waste collection corporation were included; 171 men worked in direct contact with domestic solid waste and 130 did not. Sociodemographic data, working, and medical history were assessed. The decayed, missing, and filled permanent teeth (DMFT) index was examined. Logistic regression analysis was used to identify factors associated with dental status with a significance level of 5\%. The overall mean DMFT score was 8.36 \pm 5.64 . The mean DMFT, missing teeth (MT), and filled teeth (FT) were significantly higher in workers who did not have any direct contact with waste $(p \leq 0.04)$. In the logistic analysis, DMFT $\geq 8$ was only associated with older age (OR=8.41 $[95 \%$ confidence interval (95\%CI), 5.01-14.12], $p<0.001)$. Decayed teeth (DT) $\geq 2$ was associated with no previous oral hygiene instruction $(\mathrm{OR}=2.70$ $[1.50-4.81], p=0.001)$ and no daily dental flossing $(\mathrm{OR}=4.26[1.92-9.43], p<0.001)$. MT $\geq 9$ was associated with lower education level $(\mathrm{OR}=3.33$ [1.57-7.10], $p=0.002)$. $\mathrm{FT} \geq 3 \mathrm{had}$ a negative association with low income $(\mathrm{OR}=0.42[0.25-0.70], p<0.001)$ and no daily flossing $(\mathrm{OR}=0.42[0.23-0.76], p=0.004)$. In conclusion, occupational exposure to domestic solid waste was not associated with poor dental status. Instead, age, education, income level, and oral hygiene were associated with dental health status. Missing teeth constituted the major component of the DMFT index. Therefore, prevention and oral rehabilitation programs are necessary to improve dental health.
\end{abstract}

Keywords Waste workers $\cdot$ Occupational health $\cdot$ DMF index $\cdot$ Dental caries $\cdot$ Epidemiology $\cdot$ Cross-sectional studies

\section{Introduction}

Waste management, including collection, transport, sorting, processing, and disposal, is an issue of social concern owing

Patrícia Ramos Cury and Jean Nunes dos Santos contributed equally to this work.

Responsible Editor: Lotfi Aleya

Patrícia Ramos Cury

patcury@yahoo.com

1 Post-Graduate Program in Dentistry and Health, School of Dentistry, Federal University of Bahia, Salvador, Bahia, Brazil

2 Social and Pediatric Dentistry Department, Dentistry School, Bahia Federal University, Salvador, Bahia, Brazil

3 Department of Health, Feira de Santana State University, Feira de Santana, Bahia, Brazil to its environmental influence and its effects on public health. In this context, waste workers play an essential role. They are exposed to a variety of physical, chemical, mechanical, biological, ergonomic, and social hazards in the workplace and to
4 Department of Biosciences, Federal University of Sao PauloUNIFESP, Santos, São Paulo, Brazil

5 Department of Periodontics, School of Dentistry, Federal University of Bahia, Salvador, Bahia, Brazil

6 Faculdade de Odontologia, Federal University of Bahia, Av. Araújo Pinho, no. 62, Canela, Salvador, Bahia 40110-150, Brazil

7 Department of Oral Pathology, School of Dentistry, Federal University of Bahia, Salvador, Bahia, Brazil 
environmental contaminants, which make them vulnerable to occupational health problems (Zolnikov et al. 2018). Regarding the biological contaminants, truly pathogenic bacteria (Bacillus spp., Escherichia coli, Klebsiella spp., Micrococcus spp., Proteus spp., Pseudomonas spp., Serratia spp., Staphylococcus aureus, Staphylococcus spp., and Streptococcus spp.), fungi (Aspergillus flavus, Aspergillus fumigatus, Aspergillus niger, Fusarium spp., Mucor spp., Rhizopus), and viruses (Torque teno virus and human adenovirus) have been isolated from the domestic solid waste (Obire et al. 2002).

The handling of solid waste at work results in exposure to multiple biological agents, including infectious pathogens, as well as to infectious and non-infectious aerosols containing fungi, bacteria, mycotoxins, endotoxins, and glucans (Wouters et al. 2006; Mol and Caldas 2020; Yousefi et al. 2021). There is increasing evidence that waste management work has been associated with respiratory disorders (Bünger et al. 2007), gastrointestinal disorders, musculoskeletal disorders, dermatological problems, hearing loss, and a high prevalence of viral infections (Kuijer et al. 2010; Zolnikov et al. 2018). Adverse oral health effects were also identified, including tooth damage, toothache, as well as increased cytotoxicity in buccal mucosa cells (Ivens et al. 1998; Andrade et al. 2017; Brina et al. 2018; Da Silva et al. 2018; Zolnikov et al. 2018). Of particular importance, strong evidence is available to show that biological agents' exposure exceeded generally accepted recommendations in waste collecting (Kuijer et al. 2010). Considering the daily occupational exposure to a wide variety of opportunistic pathogens, and that oral dysbiosis possibility may drive oral diseases such as dental caries (Takeshita et al. 2016), direct exposure to domestic solid waste may also be involved in the pathogenesis of dental caries.

Dental caries is one of the most prevalent chronic diseases and the most common oral condition worldwide and is considered the main indicator of oral health (Dye et al. 2012; Bukhari 2020). This is a disease where multiple factors act together in highly complex processes and cause the bacterial community to change in balance to a dysbiotic community. The dysbiotic community can decrease the salivary $\mathrm{pH}$ and favor the proliferation of aciduric bacteria that will produce additional acid, resulting in the demineralization of dental hard tissue (Pitts et al. 2017). However, other factors beyond the biological are involved in the dental caries pathogenesis, such as societal and individual factors (Holst et al. 2001). In this context, dysbiosis may occur due to exposure to bacteria, fungi, and virus present in domestic solid waste, and its interplay with biological determinants (e.g., microbes and saliva profile) and behavioral, contextual and societal factors among waste collectors may affect dental caries epidemiology. Nonetheless, the impact of occupational exposure to solid waste on dental caries is unknown so far. Therefore, the purpose of this cross-sectional study was to evaluate dental health status and its association with occupational exposure to domestic solid waste. It was hypothesized that a higher decayed, missing, and filled permanent teeth (DMFT) index is related to direct contact with solid waste at work.

\section{Material and methods}

\section{Ethical issues}

The present study was conducted in accordance with the World Medical Association Declaration of Helsinki and was approved by the Ethics and Research Committee of the School of Dentistry of the Federal University of Bahia (UFBA), Brazil (protocol 1.023.054). All participants were adults (aged $>18$ years), received detailed explanations regarding the study, and signed a detailed consent form.

\section{Study design and sampling procedures}

This cross-sectional study was performed in a convenience population of 301 consecutively screened adult male individuals who were registered as workers at a municipal waste management company. This company is responsible for the routine collection and transport to a disposal site of domestic waste from private homes from most of the city (Revita Engenharia Sustentável, Salvador, Brazil; Fig. 1). Domestic waste collected contains a wide variety of materials, including food waste, paper, plastic, tetra pack, cans, newspaper, glass bottles, cardboard boxes, aluminum foil, and wood pieces.

Direct contact with domestic solid waste was the exposure factor, and the DMFT index was the outcome. All recruited subjects worked 40 hours a week. Employees with direct contact with domestic solid waste had 8 hours exposition/day, 5 days/week. Their work consisted of gathering and transferring the waste from the residential neighborhoods to the collection vehicle. The non-exposed individuals worked as drivers, mechanics, technicians and managers.

Sociodemographic data (age, income and education level), oral hygiene (previous instructions for self-performed oral hygiene, brushing, and flossing frequency) and environmental factors (smoking and drinking habits) were considered independent variables.

The inclusion criteria were male sex and age $\geq 18$ years. The exclusion criteria were the presence of non-controlled systemic diseases, including severe uncontrolled metabolic disease, cardiopulmonary failure, active uncontrolled infection, and radiation therapy or chemotherapy to treat cancer. Women were also excluded from the study because they represented a very small proportion of workers. 


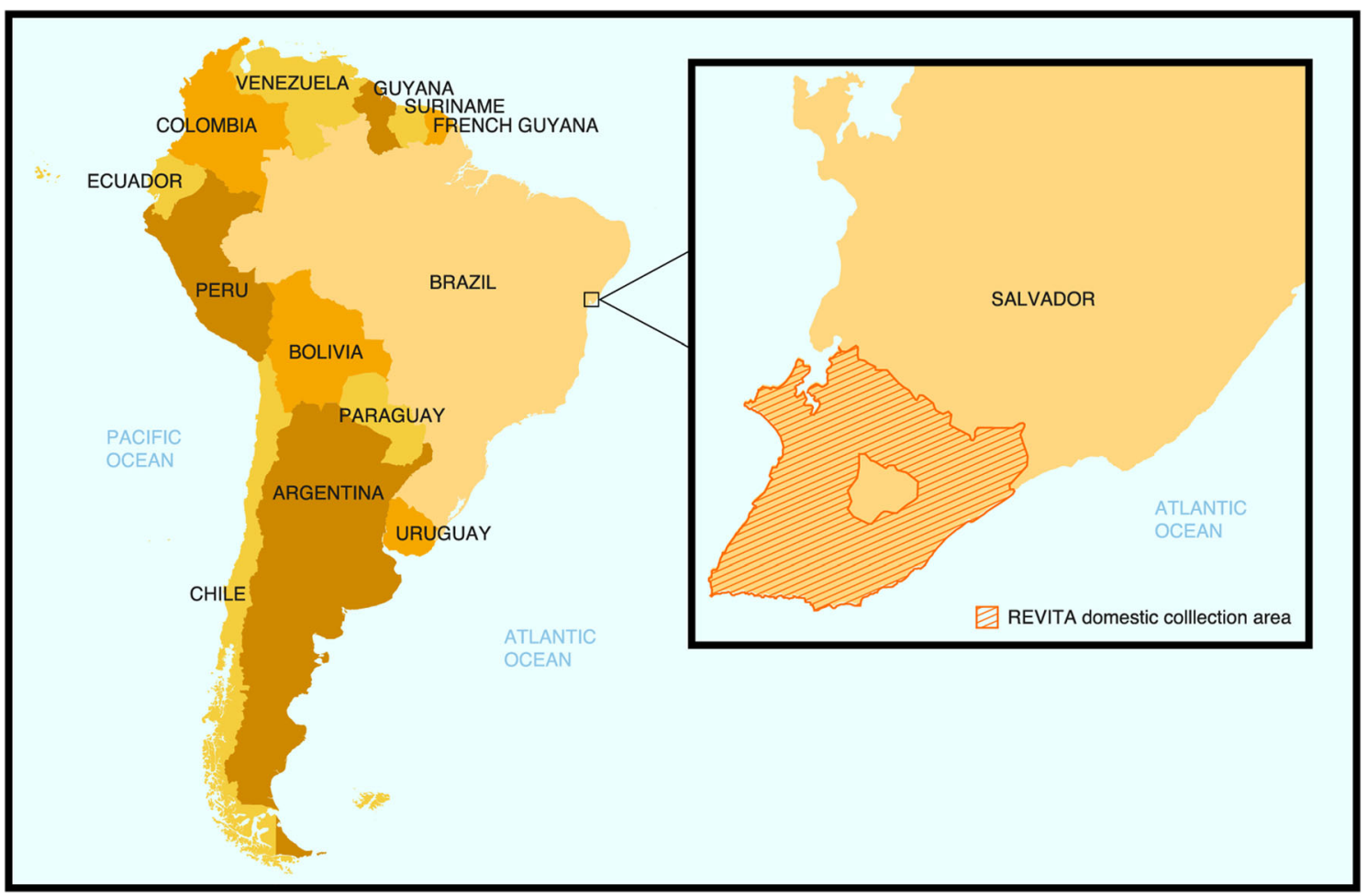

Fig. 1 Map showing REVITA's municipal practice area. Other waste management companies are responsible for the other areas of the municipality

\section{Operational procedures}

Data collection was performed between September 2016 and March 2017. Initially, in-person interviews were conducted by a trained researcher using a structured form to collect the following data: age, education level, monthly income, position held, employment time, shift work, medical history (any current or previous disease and current medication use), smoking habits, alcohol dependence (Bohn et al. 1995), brushing and flossing frequencies, and previous professional instruction for self-performed oral hygiene.

\section{Oral clinical examinations}

One dentist performed the clinical examinations, assisted by one trained graduate student, both from the School of Dentistry of the UFBA. Before clinical data collection, the examiner underwent accuracy and repeatability calibration using 10 individuals not related to the study in the same settings of the study (intraclass coefficient $=0.89$ ).

Clinical examinations were performed at the Revita Engenharia Sustentável Company headquarters, under natural light and with the individuals seated on common chairs. All fully erupted teeth, excluding the third molars, were examined using a plain mouth mirror and wooden spatula. Tooth surfaces were dried with gauze, when necessary. The dental examination consisted of assessing decayed permanent teeth (DT), missing permanent teeth (MT), or filled permanent teeth
(FT), based on the World Health Organization criteria (Petersen and Baez 2013). A tooth was diagnosed as "sound" if it had no evidence of restorative treatment or untreated dental caries; "decayed" if it had cavitation of the enamel or dentinal involvement or both, or if it had visible caries that was contiguous with a restoration, or if it had total/partial coronary destruction resulting from disease evolution; "filled" if it contained one or more permanent restorations; and "missing" if it had been extracted due to dental caries. In unclear cases, the tooth was classified as "sound."

\section{Data analysis}

The statistical analysis included 301 individuals. The missing data were omitted from the analysis.

The dependent variables in the analysis consisted of the DMFT index and its components. The variable categorization was based on the median value or World Health Organization criteria as $0-7$ or $\geq 8$ teeth for DMFT, $0-2$ or $\geq 3$ teeth for FT, $0-1$ or $\geq 2$ for DT, and $0-8$ or $\geq 9$ for MT (WHO 2013). According to the median age, subjects were divided into those aged $\leq 37$ years and those aged $\geq 38$ (38-61) years. Education level was categorized as $\geq 9$ years of education (i.e., participants who completed elementary and middle school) and $<9$ years of education (i.e., participants who had not completed elementary or middle school) (Ganzeboom and Schröder 2015). Economic status was categorized as monthly income $\leq \mathrm{US} \$ 250.00$ and monthly income $>$ US $\$ 250.00$ (US\$250.00 
was equivalent to the Brazilian minimum wage during the period of data collection). According to the median, employment time was categorized as $\leq 4$ years or $>4$ years. The work shift was categorized as either day shift or night shift.

Individuals were classified as either alcohol-dependent (based on an AUDIT test for alcohol use disorder score $\geq 8$ ) or as alcohol-nondependent (Bohn et al. 1995), and as current non-smokers or smokers.

Regarding personal oral hygiene, subjects were categorized as those who had received previous instructions for selfperformed oral hygiene and those who had not, subjects who brushed their teeth less than twice a day and those who brushed two or more times a day, and those who used dental floss daily and those who did not use dental floss daily.

First, a descriptive analysis was performed, calculating the absolute and relative frequencies for the categorical variables, while mean and standard deviation (SD) were obtained for continuous variables. In sequence, the chi-square test and backward stepwise logistic regression were used to assess the associations between the DMFT index, DT, MT, and FT (i.e., the dependent variables), and independent variables ( $p \leq$ 0.05 ). For the regression analysis, variables were included in the model when the $p$-value was $\leq 0.10$ in the chi-square test. The odds ratios (ORs) and 95\% CIs were then calculated.

In addition, the mean DMFT, DT, MT, and FT were compared between participants who worked in direct contact with domestic waste and those who did not using Student's t-test, according to the normality and homoscedasticity of the data as verified using the Kolmogorov-Smirnov test and Levene's tests, respectively. The chosen level of significance was $5 \%$.

Data were analyzed using a statistical software program (SPSS version 15.0, SPSS Inc., Chicago, IL, USA).

\section{Results}

Table 1 shows the general characteristics of the sample. The sociodemographic analysis showed that a higher percentage of participants were aged $\leq 37$ years (52.8\%), had $\geq 9$ years of education (61.1\%), and had an income $\leq 250$ US\$/month $(54.3 \%)$. Regarding occupational characteristics, $43.2 \%$ had direct contact with domestic solid waste, $50.5 \%$ had been working at this company for between 5 and 30 years, and $77.1 \%$ worked in the day shift. Most participants reported having received previous instructions for self-performed oral hygiene (76.4\%); $93 \%$ brushed their teeth two or more times a day, but only $24.9 \%$ used dental floss daily. Almost $46.5 \%$ of the participants reported alcohol dependence, and $16.9 \%$ reported smoking habits. Furthermore, 5.6\% of the volunteers reported hypertension and/or diabetes and were under medication for these conditions.

The overall mean DMFT score was $8.36 \pm 5.6$, with $1.14 \pm$ 1.6 of DT, $4.10 \pm 4.7$ of MT, and $3.13 \pm 3.5$ of FT (Table 1).
Table 1 General characteristics of the whole sample (urban cleaning workers in Brazil; $N=301$ )

\begin{tabular}{|c|c|}
\hline Variables & $N$, valid percentage $(\%)$ or mean $\pm \mathrm{SD}$ \\
\hline \multicolumn{2}{|l|}{ Sociodemographic factors } \\
\hline \multicolumn{2}{|l|}{ Age (years) } \\
\hline Mean $( \pm \mathrm{SD})$ & $37.75 \pm 8.68$ \\
\hline$\leq 37$ & $159(52.8 \%)$ \\
\hline$\geq 38$ & $142(47.2 \%)$ \\
\hline \multicolumn{2}{|c|}{ Education level (years of study) } \\
\hline$<9$ & $117(38.9 \%)$ \\
\hline$\geq 9$ & $184(61.1 \%)$ \\
\hline \multicolumn{2}{|l|}{ Monthly income (US\$) } \\
\hline$\leq 250.00$ & $163(54.3 \%)$ \\
\hline$>250.00$ & $137(45.7 \%)^{\mathrm{a}}$ \\
\hline \multicolumn{2}{|l|}{ Occupational factors } \\
\hline \multicolumn{2}{|l|}{ Position held } \\
\hline Non-operational worker & $171(56.8 \%)$ \\
\hline Operational worker & $130(43.2 \%)$ \\
\hline \multicolumn{2}{|l|}{ Employment time (years) } \\
\hline Mean $\pm \mathrm{SD}$ & $7.3( \pm 6.8)$ \\
\hline$\leq 4$ & $153(50.8 \%)$ \\
\hline $5-30$ & $148(49.2 \%)$ \\
\hline \multicolumn{2}{|l|}{ Work shift } \\
\hline Day shift & $232(77.1 \%)$ \\
\hline Night shift & $69(22.9 \%)$ \\
\hline \multicolumn{2}{|l|}{ Oral hygiene } \\
\hline \multicolumn{2}{|c|}{ Previous self-performed oral hygiene instructions } \\
\hline Yes & $230(76.4 \%)$ \\
\hline No & $71(23.6 \%)$ \\
\hline \multicolumn{2}{|l|}{ Toothbrushing frequency } \\
\hline$\geq 2 \times /$ day & $280(93.0 \%)$ \\
\hline$<2 \times /$ day & $21(7.0 \%)$ \\
\hline \multicolumn{2}{|l|}{ Dental flossing daily } \\
\hline Yes & $75(24.9 \%)$ \\
\hline No & $226(75.1 \%)$ \\
\hline \multicolumn{2}{|l|}{ Medical history } \\
\hline \multicolumn{2}{|c|}{ Treatment of systemic diseases* } \\
\hline No & $284(94.4 \%)$ \\
\hline Yes & $17(5.6 \%)$ \\
\hline \multicolumn{2}{|l|}{ Environmental factors } \\
\hline \multicolumn{2}{|l|}{ Alcohol dependence } \\
\hline No & $161(53.5 \%)$ \\
\hline Yes & $140(46.5 \%)$ \\
\hline \multicolumn{2}{|l|}{ Smoking habits } \\
\hline No & $250(83.1 \%)$ \\
\hline Yes & $51(16.9 \%)$ \\
\hline \multicolumn{2}{|l|}{ Dental status } \\
\hline \multicolumn{2}{|l|}{ Decayed teeth } \\
\hline Mean $\pm \mathrm{SD}$ & $1.14 \pm 1.62$ \\
\hline $0-1$ tooth & $214(71.1 \%)$ \\
\hline$\geq 2$ teeth & $87(28.9 \%)$ \\
\hline
\end{tabular}


Table 1 (continued)

\begin{tabular}{ll}
\hline Variables & $N$, valid percentage $(\%)$ or mean \pm SD \\
\hline $\begin{array}{l}\text { Missed teeth } \\
\text { Mean } \pm \text { SD }\end{array}$ & $4.10 \pm 4.71$ \\
$0-8$ teeth & $269(86.4 \%)$ \\
$\geq 9$ teeth & $41(13.6 \%)^{\mathrm{a}}$ \\
Filled teeth & \\
Mean \pm SD & $3.13 \pm 3.47$ \\
$0-2$ tooth & $167(55.5 \%)$ \\
$\geq 3$ teeth & $134(44.5 \%)$ \\
DMFT & \\
Mean \pm SD & $8.36 \pm 5.64$ \\
$0-7$ teeth & $160(53.2 \%)$ \\
$\geq 8$ teeth & $141(46.8 \%)$ \\
\hline
\end{tabular}

$N$, number of subjects; $S D$, standard deviation; US\$, US dollars; $D M F T$, decayed, missing, filled teeth index

${ }^{\text {a }}$ One missing information

*Subjects which reported hypertension and/or diabetes and were under medication use

The mean DMFT, MT, and FT were significantly higher in workers who did not have any direct contact with waste $(p \leq$ $0.04)$, but the mean DT did not differ between groups $(p=$ 0.151 ; Fig. $2 \mathrm{a}-\mathrm{d})$.

In accordance with bivariate analysis (Table 2), those factors that had a $p \leq 0.10$ were included in multiple regression analysis model. In the regression analysis, including age, education level, operational position, employment time, work shift, and smoking habits in the model, DMFT index $\geq 8$ was

significantly associated with older age (OR, 8.41; 95\% CI, 5.01-14.12; $p<0.001$; Table 3). Other variables were not significantly associated with the DMFT index. DT $\geq 2$ was associated with no previous instruction for self-performed oral hygiene (OR, 2.70; 95\% CI, 1.50-4.81; $p=0.001)$ and no daily flossing (OR, 4.26; 95\% CI, 1.92-9.43; $p<0.001$; Table 3). Income, previous oral hygiene instruction, and daily flossing were included in the model. In addition, $\mathrm{MT} \geq 9$ was significantly associated with lower education level (OR, 3.33; 95\% CI, 1.57-7.10; $p=0.002$; Table 3), including age, education level, and employment time in the model. Finally, FT $\geq 3$ was negatively associated with lower income (OR, 0.42 ; 95\% CI, $0.25-0.70 ; p<0.001)$ and no daily flossing (OR, 0.42; 95\% CI, 0.23-0.76; $p=0.004$; Table 3). Age, income, employment time, previous oral hygiene instruction, daily flossing, alcohol dependence, and smoking habits were included in the model. The other variables were not significantly associated with DT, MT, or FT.

\section{Discussion}

In the present study, dental caries and its risk indicators were assessed among domestic waste employees with the main focus on the evaluation of the effect of direct occupational contact with domestic solid waste. The results showed that the DMFT index and its components were not associated with direct contact with domestic waste, but were associated with older age, lower income and education, no previous instruction for self-performed oral hygiene, and no daily flossing. Therefore, the original hypothesis was not confirmed.
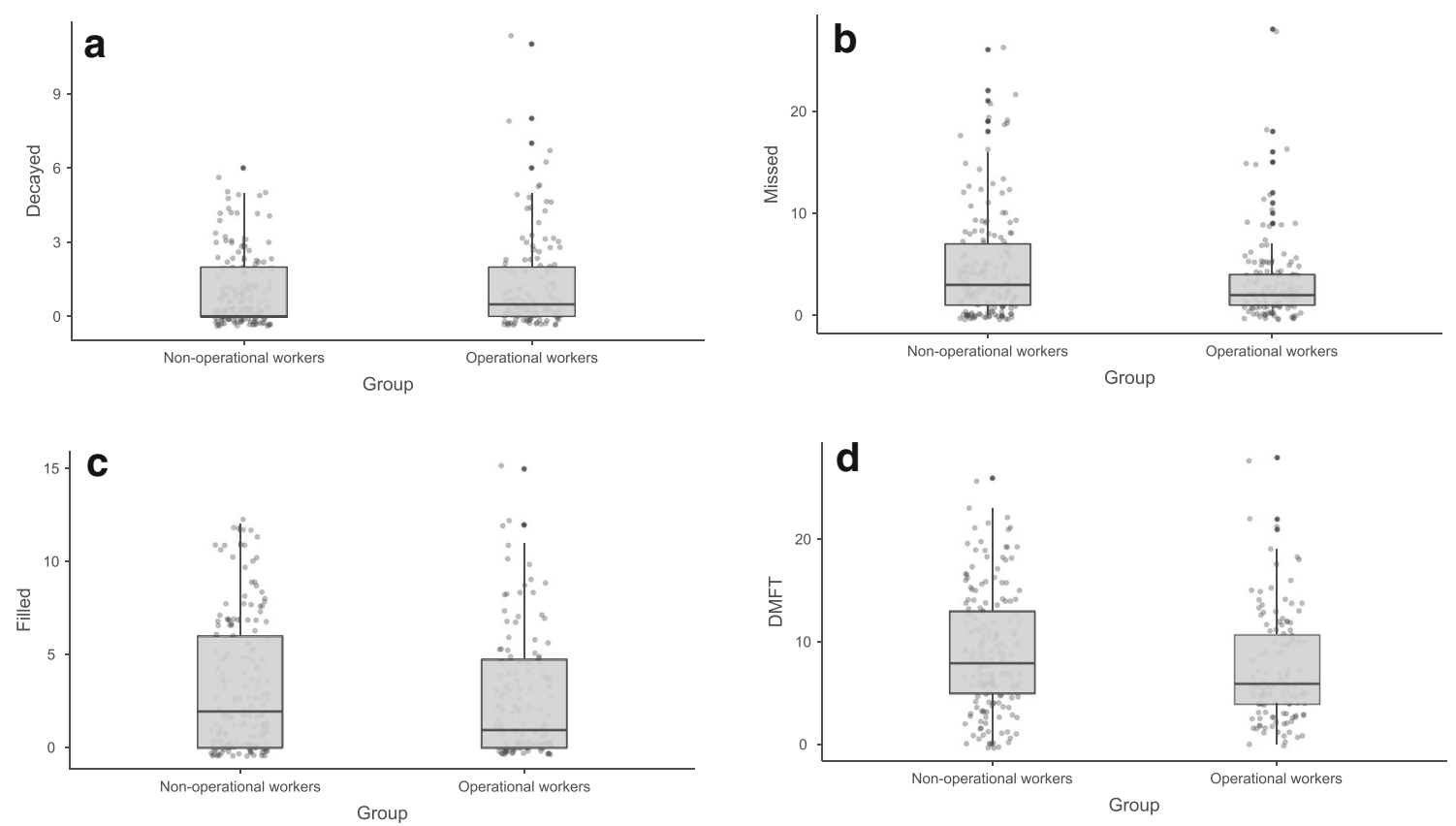

Fig. 2 Dental variables of operational and non-operational workers. a Decayed teeth. b Missed teeth. $\mathbf{c}$ Filled teeth. d DMFT index 
Table 2 Bivariate analysis of the association between dental health status with putative risk factors in urban cleaning workers in Brazil $(N=301)$

\begin{tabular}{lllll}
\hline Factors & Odds ratio $(95 \% \mathrm{CI})$ & & & \\
\cline { 2 - 5 } & DMFT $\geq 8$ & Decayed $\geq 2$ & Missed $\geq 9$ & Filled $\geq 3$ \\
\hline Higher age & $8.41(5.01-14.12)^{*}$ & $0.82(0.50-1.35)$ & $1.41(1.27-1.56)^{*}$ & $2.24(1.41-3.56)^{*}$ \\
Lower education & $1.64(1.01-2.68)^{*}$ & $1.23(0.73-2.10)$ & $3.40(1.73-6.68)^{*}$ & $0.74(0.45-1.21)$ \\
Lower income & $0.87(0.55-1.37)$ & $1.56(0.94-2.60)^{*}$ & $1.22(0.62-2.38)$ & $0.40(0.25-0.63)^{*}$ \\
Direct contact with waste & $0.52(0.33-0.83)^{*}$ & $1.42(0.86-2.35)$ & $0.58(0.28-1.14)$ & $0.72(0.46-1.15)$ \\
Employment time $>4$ years & $2.61(1.64-4.18)^{*}$ & $0.73(0.44-1.21)$ & $3.80(1.78-8.05)^{*}$ & $2.28(1.43-3.63)^{*}$ \\
Night shift work & $0.57(0.33-0.98)^{*}$ & $1.00(0.56-1.82)$ & $0.54(0.21-1.33)$ & $0.75(0.43-1.30)$ \\
No previous oral hygiene instructions & $0.67(0.40-1.16)$ & $2.83(1.62-4.94)^{*}$ & $0.76(0.33-1.73)$ & $0.56(0.32-0.97)^{*}$ \\
Toothbrushing <2×/day & $1.03(0.42-2.51)$ & $1.94(0.78-4.80)$ & $1.54(0.50-4.84)$ & $1.14(0.47-2.78)$ \\
No dental flossing daily & $0.66(0.40-1.11)$ & $4.50(2.06-9.84)^{*}$ & $1.72(0.73-4.06)$ & $0.37(0.22-0.64)^{*}$ \\
Alcohol dependence & $0.78(0.50-1.23)$ & $1.34(0.81-2.21)$ & $0.80(0.40-1.54)$ & $0.64(0.40-1.01)$ \\
Smoking habits & $0.41(0.21-0.80)^{*}$ & $1.03(0.53-2.00)$ & $0.82(0.32-2.06)$ & $0.28(0.14-0.58)^{*}$ \\
\hline
\end{tabular}

$C I$, confidence interval; DMFT, decayed, missing, filled teeth

$p \leq 0.10$

$* p \leq 0.05$

Significantly higher mean DMFT, MT, and FT were observed in the present group of non-collectors than in collectors, while the

Table 3 Multiple logistic regression analysis of the relationship between the DMFT index, decayed teeth, missed teeth, and filled teeth, and its associated factors in urban cleaning workers in Brazil

\begin{tabular}{lll}
\hline Variable & Odds ratio (95\% CI) & $p$ \\
\hline DMFT $^{\text {a }}$ & & \\
Age (years) & & $<0.001$ \\
$\leq 37$ & $8.41(5.01-14.12)$ & \\
$\geq 38$ & & \\
Decayed teeth & & \\
Previous oral hygiene instructions & 1 & \\
Yes & $2.70(1.50-4.81)$ & \\
No & & \\
Dental flossing daily & 1 & \\
Yes & $4.26(1.92-9.43)$ & \\
No & & \\
Missed teeth & & \\
Education level & 1 & \\
$\geq 9$ & $3.33(1.57-7.10)$ & \\
$<9$ & & \\
Filled teeth & & \\
Monthly income (US\$) & 1 & \\
$>250.00$ & $0.42(0.25-0.70)$ & \\
$\leq 250.00$ & & \\
Dental flossing daily & & \\
Yes & & \\
No & & \\
\hline & & \\
\hline
\end{tabular}

${ }^{\mathrm{a}}$ DMFT - decayed, missed, and filled permanent teeth index mean DT was similar between groups. Furthermore, the regression analysis did not show any association between exposure to solid waste and dental caries. Therefore, direct occupational contact with domestic solid waste was not associated with dental caries. However, waste collectors are exposed daily to a variety of occupational hazards, including infectious pathogens, that can enter the host through direct contact with waste or inhalation, resulting in a wide range of other health effects (Ivens et al. 1998; Kuijer et al. 2010; Andrade et al. 2017; Brina et al. 2018; Da Silva et al. 2018; Zolnikov et al. 2018). The exposition to virus, fungi and bacteria from the domestic waste may cause a dysbiosis of the oral microbiome, driving the polymicrobial communities towards pathogenicity with a particular emphasis on cariogenic biofilm development, which will be able to produce acid and cause the demineralization of the tooth surface. However, the adherence of present workers to the use of personal protective equipment as a preventive measure to reduce exposure to harmful substances might have avoided this effect. In particular, continuous training of workers is required to make them aware of occupational risks and the importance of work safety. Waste collectors must also adhere to good personal hygiene, especially before eating and when leaving the workplace, so that microorganisms and harmful chemicals are unable to be absorbed inside the body or transmitted to other environments or people. By contrast, a significant association has been reported between dental caries and occupation in the cement industry (Bozyk and Owczarek 1990), petrochemical industry (Werckmeister and Ruppe 1990; Duffy 1996), agriculture (Blignaut and Grobler 1992), and in particular, in the food industry where the occurrence of dental caries in bakery workers was sufficient to characterize it as an occupational disease (Sonnamend et al. 1991). 
The worse dental status of the non-collector group was due to their higher FT and MT. It could be suggested that the noncollector group had greater access to dental treatment, but this was not based on a preventive approach but on tooth restorations and extractions after the progression of dental caries, and perhaps the progression of periodontal disease. It can also be assumed that due to the low income and educational levels of the whole group of workers, most did not seek dental care periodically, and when they did, restorations and extractions were required. A preventive program associated with oral rehabilitation is required to improve the oral health of this population. However, the DMFT of the whole sample and the groups of collectors and non-collectors were within the low and moderate grade of caries prevalence as indicators of oral health (Petersen and Baez 2013). These values were also lower than the rates from the latest Brazilian nationwide oral health survey (Ministry of Health of Brazil 2011) that found a DMFT index of around 16 in people aged between 35 and 44 years, and also lower than that in workers in the textile industry (Cavalcanti et al. 2017), supermarket chains (Batista et al. 2013), and building construction (Tomita et al. 2005), who had a DMFT score of over 11. The current findings are consistent with the results of a study involving employees monitored by an inter-company Occupational Health Service in France, where the DMFT score was approximately 9 (Catteau et al. 2013). Conversely, cross-sectional studies reported DMFT scores lower than 5.5 among workers from different sectors, such as green marble mining and industrial workers (Ahlberg et al. 1996; Dagli et al. 2008). The difference in prevalence in these studies is likely associated with the difference in exposure to risk factors among populations, as dental caries is a multifactorial disease with various factors involved in its pathogenesis, including the presence of fermentable sugars and cariogenic microbial microorganisms, and host and environmental factors (Rathee and Sapra 2020), as well as access to dental caries.

A theoretical model of dental caries, involving contextual, social, and biological factors, has been outlined by Holst et al. (2001), focused on the understanding of caries and its variations in populations. The theoretical framework directs attention to health effects of collective phenomena that cannot be reduced to individual attributes, as dental caries are a result of biological processes on tooth surfaces and of processes in the environment. Accordingly, the environmental process is a combined result of behavioral, contextual and societal factors, which in a series of steps ultimately influence the way dental caries develop. The occurrence of caries is thus an outcome of complex processes in the oral cavity and of behaviors of individuals and societies. Even though the association between occupational exposure to domestic solid waste was not significant, the present results fit in this theoretical framework, with associations with older age, lower income and education, daily flossing, and previous oral hygiene instructions being significant. In workers from other sectors, DMFT was associated with older age (Tomita et al. 2005; Batista et al. 2013; Cavalcanti et al. 2017). This suggests that oral health problems accumulate over the years and that older individuals were not exposed to preventive care. Similar to other health conditions, lower education levels had a negative effect on tooth loss, consistent with other studies (Tomita et al. 2005; Batista et al. 2013; Mahdi et al. 2016; Cavalcanti et al. 2017; Zaitsu et al. 2017), which suggests that tooth extraction was common among these workers, probably due to the limited access to early and regular dental care, favoring the evolution of dental caries and tooth loss. Furthermore, a higher dental caries rate was associated with a lack of oral hygiene instruction and no daily flossing, and a higher filling rate was associated with higher monthly income and not using dental floss daily. This was likely due to the fact that a higher income increased access to preventive and restorative treatment, as well as dental hygiene products (Wamala et al. 2006; Costa et al. 2012; Molarius et al. 2014).

This study has a few limitations. The analysis of a convenience sample in a single company and performing a clinical examination at their workplace may lead to poor representation of the at-risk population. For this reason, other waste collection companies should be studied in the future. In addition, due to performing the clinical examination at their workplace, subjects with negative self-perception of their oral health may refuse to participate to avoid personal exposure. However, the analysis was performed with an adequate sample size and a power of 0.8 for the DMFT values in a onesided test with an alpha of 0.05 . Moreover, this cross-sectional study simultaneously measured exposure and health outcomes; therefore, it is not possible to draw conclusions on the cause-effect relationship. Therefore, longitudinal studies should be planned to establish a temporal relationship between these variables.

The results of this study may be used to plan an oral health program for this population, which may affect general health and psychosocial development and even reduce absenteeism from work. The oral health program should be based on preventive care, focusing on education and instructions for selfperformed oral hygiene and prosthetic rehabilitation of edentulism. Furthermore, at the moment, it is possible that the domestic waste is infected by severe acute respiratory syndrome coronavirus 2 (SARS-CoV-2), which may pose additional risks to domestic waste collectors and the environment (Mol and Caldas 2020). In particular, the spread of the coronavirus may be increased by inadequate waste management.

\section{Conclusions}

Occupational exposure to domestic solid waste was not associated with poor dental status. Instead, age, education, income 
level, and oral hygiene were associated with dental health status. Missing teeth constituted the major component of the DMFT index. Therefore, prevention and oral rehabilitation programs are necessary to improve dental health.

Acknowledgements The authors acknowledge the waste management company (Revita Engenharia Sustentável, Salvador, Bahia, Brazil) and the National Council for Scientific and Technological Development (Processes: 303861/2018-5 and 308128/2016-8).

Author contribution MCA collected the data. NSA and PCR performed the statistical analysis, interpreted the results, and drafted the manuscript. MCTC, ISGF and DAR participated in the discussion of study design and interpretation of the results and revised the manuscript. JNS and MIPV designed the study and revised the manuscript. All authors read and approved the final manuscript.

Funding The authors would like to thank The National Council for Scientific and Technological Development (CNPq, Brazil, grant no. $303861 / 2018-5$ and 308128/2016-8). The funders had no role in the study design, collection, analysis or interpretation of the data, writing the manuscript, or the decision to submit the paper for publication.

Availability of data and materials The data that support the findings of this study are available on request from the corresponding author. The data are not publicly available due to their containing information that could compromise the privacy of research participants.

\section{Declarations}

Ethics approval and consent to participate The present study was conducted in accordance with the World Medical Association Declaration of Helsinki criteria and was approved by the Ethics and Research Committee of the School of Dentistry of the Federal University of Bahia (UFBA), Brazil (protocol 1.023.054). Individuals who agreed to participate signed an informed consent form.

\section{Consent for publication Not applicable}

Competing interests The authors declare no competing interests.

\section{References}

Ahlberg J, Tuominen R, Murtomaa H (1996) Subsidized dental care improves caries status in male industrial workers. Community Dent Oral Epidemiol 24:249-252. https://doi.org/10.1111/j.16000528.1996.tb00854.x

Andrade MC, Dos Santos JN, Cury PR, Flygare AC, Claudio SR, Oshima CT, Ribeiro DA (2017) Cytogenetic biomonitoring in buccal mucosal cells from municipal solid waste collectors. Anticancer Res 37: 849-852. https://doi.org/10.21873/anticanres.11388

Batista MJ, Rihs LB, de Sousa MLR (2013) Workers oral health: a crosssectional study. Braz. J. Oral Sci 12:178-183. https://doi.org/10. 1590/s1806-83242012000500003

Blignaut JB, Grobler SR (1992) High fruit consumption and the periodontal status of farm workers. Clin Prevent Dent 14:25-27

Bohn MJ, Babor TF, Kranzler HR (1995) The alcohol use disorders identification test (AUDIT): validation of a screening instrument for use in medical settings. Journal of Studies on Alcohol and Drugs 56:423-432. https://doi.org/10.15288/jsa.1995.56.423

Bozyk A, Owczarek B (1990) Incidence of parodontal diseases in workers of the Chelm Cement Plant exposed to cement dust. Czasopismo Stomatologiczne 43:375-380

Brina KR, Carvalho TS, Ardenghi PG, Basso da Silva L (2018) Micronuclei and other nuclear anomalies in exfoliated buccal cells of urban solid waste collectors and recyclers in southern Brazil. Chemosphere 193:1058-1062. https://doi.org/10.1016/j. chemosphere.2017.11.119

Bukhari OM (2020) Dental caries experience and oral health related quality of life in working adults. Saudi Dent J 32(8):382-389. https://doi. org/10.1016/j.sdentj.2019.11.003

Bünger J, Schappler-Scheele B, Hilgers R, Hallier E (2007) A 5-year follow-up study on respiratory disorders and lung function in workers exposed to organic dust from composting plants. Int Arch Occup Environ Health 80:306-312. https://doi.org/10.1007/s00420006-0135-2

Catteau C, Blaizot A, Duhamel A, Delzenne A, Devillers A, Frimat P (2013) Santé dentaire et facteurs associés dans un service de santé au travail du Nord. Santé Publique 25:747-755 (in French)

Cavalcanti AFC, Fernandes LHF, Cardoso AMR, Santos JSJ, Maia EG, Cavalcanti AL (2017) Oral health status of Brazilian Workers of a textile industry. Pesq Bras Odontoped Clin Integr 17:1-8. https:// doi.org/10.4034/PBOCI.2017.171.03

Costa SM, Martins CC, Bonfim Mde L, Zina LG, Paiva SM, Pordeus IA, Abreu MH (2012) A systematic review of socioeconomic indicators and dental caries in adults. Int J Environ Res Public Health 9:3540 3574. https://doi.org/10.3390/ijerph9103540

DA Silva VHP, Andrade MC, Claudio SR, Yujra VQ, Alpire MES, Dos Santos JN, Cury PR, Ribeiro DA (2018) Genomic instability in buccal mucosal cells of municipal street sweepers as evaluated by micronucleus test. Anticancer Res 38:3123-3126. https://doi.org/ 10.21873/anticanres. 12573

Dagli RJ, Kumar S, Mathur A, Balasubrimanyam G, Duraiswamy P, Kulkarni S (2008) Prevalence of leukoplakia, oral submucous fibrosis, papilloma and its relation with stress among green marbles mine laborers, India. Med Oral Patol Oral Cir Bucal 13:E687-E692

Duffy B (1996) Dental problems in the offshore oil and gas industry: a review. Occup Med 46:79-83. https://doi.org/10.1093/occmed/46. 1.79

Dye BA, Li X, Beltran-Aguilar ED (2012) Selected oral health indicators in the United States, 2005-2008. NCHS Data Brief 96:1-8

Ganzeboom HBG, Schröder H (2015) The International Standard Classification of Education 2011 [ISCED-2011]. In: Nederland in context: verschillen en overeenkomsten. Proceedings vijfde Nederlandse Workshop European Social Survey 11-34

Holst D, Schuller AA, Aleksejuniené J, Eriksen HM (2001) Caries in populations-a theoretical, causal approach. Eur J Oral Sci 109: 143-148. https://doi.org/10.1034/j.1600-0722.2001.00022.x

Ivens UI, Lassen JH, Kaltoft BS, Skov T (1998) Injuries among domestic waste collectors. Am J Ind Med 33:182-189

Kuijer PP, Sluiter JK, Frings-Dresen MH (2010) Health and safety in waste collection: towards evidence-based worker health surveillance. Am J Ind Med 53:1040-1064. https://doi.org/10.1002/ajim. 20870

Mahdi SS, Sibilio F, Amenta F (2016) Dental hygiene habits and oral health status of seafarers. Int Marit Health 67:9-13. https://doi.org/ 10.5603/IMH.2016.0003

Mol MPG, Caldas S (2020) Can the human coronavirus epidemic also spread through solid waste? Waste Manag Res 38:485-486. https:// doi.org/10.1177/0734242X20918312

Molarius A, Simonsson B, Lindén-Boström M, Kalander-Blomqvist M, Feldman I, Eriksson HG (2014) Social inequalities in self-reported refraining from health care due to financial reasons in Sweden: 
health care on equal terms? BMC Health Serv Res 29(14):605. https://doi.org/10.1186/s12913-014-0605-2

Obire O, Nwaubeta O, Adue BN (2002) Microbial community of a wastedump site. J Appl Sci Environ Manag 6:78-84

Petersen PE, Baez RJ (2013) Oral health surveys: basic methods-5th ed. World Health Organization, France, pp 1-140

Pitts NB, Zero DT, Marsh PD, Ekstrand K, Weintraub JA, Ramos-Gomez F, Tagami J, Twetman S, Tsakos G, Ismail A (2017) Dental caries. Nat Rev Dis Primers 25(3):17030. https://doi.org/10.1038/nrdp. 2017.30

Rathee M, Sapra A (2020) Dental caries. Treasure Island (FL): StatPearls Publishing. https://www.ncbi.nlm.nih.gov/books/NBK551699/. Accessed June, $3^{\text {rd }} 2020$

Sonnamend E, Maschinski G, Sussmann G (1991) Investigation of baker's caries in bakery and confectionary students. ZWR 100: $171-173$ (in German)

Takeshita T, Kageyama S, Furuta M, Tsuboi H, Takeuchi K, Shibata Y, Shimazaki Y, Akifusa S, Ninomiya T, Kiyohara Y, Yamashita Y (2016) Bacterial diversity in saliva and oral health-related conditions: the Hisayama Study. Sci Rep 6:22164. https://doi.org/10. 1038/srep22164

Tomita NE, Chinellato LE, Lauris JR, Kussano CM, Mendes HJ, Cardoso MT (2005) Oral health of building construction workers: an epidemiological approach. J Appl Oral Sci 13:24-27. https://doi. org/10.1590/s1678-77572005000100006

Wamala S, Merlo J, Boström G (2006) Inequity in access to dental care services explains current socioeconomic disparities in oral health: the Swedish National Surveys of Public Health 2004-2005. J Epidemiol Community Health 60:1027-1033. https://doi.org/10. 1136/jech.2006.046896
Werckmeister J, Ruppe K (1990) Prevalence of damages of dental, the oral and the jaw areas among workers exposed to substances in a chemical company. Stomatologie der DDR 40:172-174 (in German)

World Health Organization (2013) Oral health surveys: basic methods. World Health Organization 2013. https://www.who.int/oral_health/ publications/9789241548649/en/. Accessed October, 202020

Wouters IM, Spaan S, Douwes J, Doekes G, Heederik D (2006) Overview of personal occupational exposure levels to inhalable dust, endotoxin, beta(1->3)-glucan and fungal extracellular polysaccharides in the waste management chain. Ann Occup Hyg 50:3953. https://doi.org/10.1093/annhyg/mei047

Yousefi M, Oskoei V, Jonidi Jafari A, Farzadkia M, Hasham Firooz M, Abdollahinejad B, Torkashvand J (2021) Municipal solid waste management during COVID-19 pandemic: effects and repercussions. Environ Sci Pollut Res Int 3:1-10. https://doi.org/10.1007/ s11356-021-14214-9

Zaitsu T, Kanazawa T, Shizuma Y, Oshiro A, Takehara S, Ueno M, Kawaguchi Y (2017) Relationships between occupational and behavioral parameters and oral health status. Ind Health 55:381-390. https://doi.org/10.2486/indhealth.2017-0011

Zolnikov TR, da Silva RC, Tuesta AA, Marques CP, Cruvinel VRN (2018) Ineffective waste site closures in Brazil: a systematic review on continuing health conditions and occupational hazards of waste collectors. Waste Manag 80:26-39. https://doi.org/10.1016/j. wasman.2018.08.047

Publisher's note Springer Nature remains neutral with regard to jurisdictional claims in published maps and institutional affiliations. 